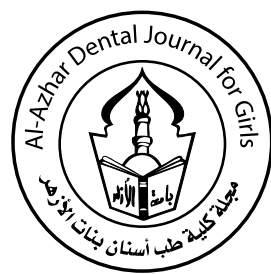

\title{
Evaluation of Subantimicrobial Dose Doxycycline Effects on Dental Implant Osseointegration in Type II Diabetic Patients
}

\author{
Nora Abd-EIrahman ${ }^{(1)}$, Ossama El-Shall ${ }^{(2)}$, Olfat Shaker ${ }^{(3)}$ and Mai Shafik $^{(4)}$
}

Codex : 27/1807

azhardentj@azhar.edu.eg

http://adjg.journals.ekb.eg

\section{KEYWORDS}

Diabetes mellitus,

Subantimicrobial dose

doxycycline, Dental implant,

Cone beam computed

tomography.

\begin{abstract}
Objective: The present study was carried out to compare radiographic outcomes of dental implant in type II diabetic patients with or without adjunctive administration of subantimicrobial dose doxycycline. Subjects and Methods : This study included 20 patients with controlled type II diabetes mellitus of both genders, their age ranged from 40-48years.The study groups were designed in two groups, test group treated with dental implant with systemic administration of subantimicrobial dose doxycycline(SDD) for twice per day for 3 months and control group received dental implant alone. Results: Regarding radiographic marginal bone levels measurements; in both groups the mean marginal bone loss increased by time, with significant difference between both groups where the test group (SDD received group) showed the lower marginal bone loss values. In both groups, bone density measurements increased by time, with significant percentage change recorded for test group (SDD received group) $55.22 \%$ while control group recorded $17.40 \%$ from base line values. Conclusions: The use of sub-antimicrobial dose doxycycline with dental implants in type II diabetic patients was effective as an adjunctive host modulatory drug. Systemic administration of subantimicrobial dose doxycycline with dental implants in type II diabetic patients resulted in greater increase in bone density and less marginal bone loss thus subantimicrobial dose doxycycline can enhance the osseointegration of dental implants.
\end{abstract}

- Extracted from PHD thesis entitle "Evaluation of Subantimicrobial Dose Doxycycline Effects on Dental Implant Osseointegration in Type II Diabetic Patients"

1. Associate Lecturer of Oral Medicine, Periodontology, Oral diagnosis and Radiology Department. Faculty of Dental Medicine for Girls. Al-Azhar University.

2. Professor of Oral Medicine, Periodontology, Oral diagnosis and Radiology Department, Vice- Dean for Postgraduate Studies. Faculty of Dental Medicine for Girls. Al-Azhar University.

3. Professor of Bio-Chemistry. Faculty of Medicine. Cairo University.

4. Associate Professor of Oral Medicine, Periodontology, Oral diagnosis and Radiology, Department. Faculty of Dental Medicine for Girls. Al-Azhar University. 


\section{INTRODUCTION}

For a long time, diabetes has been considered a relative contraindication for implant therapy, as these patients have an increased susceptibility to infection, delayed healing and micro vascular complications. Understanding of diabetes mellitus (DM) as a relative contraindication depending on the level of glycemic control has changed little since the 1988 national institute of health (NIH) conference. As a result, well-controlled diabetic patients can be treated with implants, while uncontrolled diabetic patients cannot benefit from this therapy ${ }^{(1)}$. Despite the higher risk of failure of dental implants in diabetic patients, maintaining adequate blood glucose levels along with other measures improves the implant survival rates in these patients. The biological concepts of the diabetic effects on osseointegration may be related to the advanced glycation end products (AGEs) interacting with bone-forming cells, signaling proteins, and/or extracellular matrix components. In addition, the high concentration of blood-glucose in body fluids encourages the growth of mycotic pathogens such as candida. The microangiopathy arising as a complication of diabetes may compromise the vascularization of the flap, thus delaying healing and acting as a gateway for the infection of soft tissue ${ }^{(2)}$.

Regarding host modulatory therapy (HMT), is a novel treatment approach which aims to down regulate destructive aspects and up regulate protective aspects of the immune response. Several agents have been used such as non-steroidal anti-inflammatory drugs (NSAIDS), bisphosphonates and nonantimicrobial tetracycline formulations. However, the risk benefit ratio and adverse effects of NSAIDs and bisphosphonates limit their use in periodontal treatment ${ }^{(3)}$. Doxycycline has a low minimum inhibitory concentration, highly concentrated in GCF and has substantively to bind to the tooth structure, which makes it highly advantageous to use doxycycline as a host modulatory agent. Subantimicrobial dose doxycycline (SDD) remains, at present, the only systemic host response modulator specifically indicated as an adjunctive treatment for periodontitis. The two basic mechanisms of action are the inhibition of the destructive matrix Metalloproteinases enzymes (MMPs) and the down regulation of key inflammatory cytokines IL-1 (interleukin -1), Il-6 (interleukin -6) and tumor necrosis factor- $\alpha$ (TNF- $\alpha)^{(4)}$.

The bone quality was objectively assessed with density values obtained from CBCT to determine the correlations between bone density and primary stability of dental implants ${ }^{(5)}$. Furthermore,CBCTisa useful approach for evaluating bone density changes around teeth induced by orthodontic treatment ${ }^{(6,7)}$. CBCT-enhanced bone density characterization. Beyond linear and volumetric measurements, the accuracy of CBCT to evaluate bone mineral density has also been assessed ${ }^{(8,9)}$. Since limited evidence have been present regarding utilization of SDD as a host modulatory drug with dental implant placement in diabetic patients ,therefore the present study was conducted to evaluate the modulatory effect of SDD with dental implant placement in controlled type II diabetic patients. Thus, the aim of the present study was to evaluate the effectiveness of subantimicrobial dose doxycycline (SDD) on dental implant osseointegration in controlled type II diabetic patients through radiographic analysis of bone density and marginal bone loss utilizing CBCT.

\section{SUBJECTS AND METHODS}

A total of 20 patients with type II diabetes mellitus of both genders ( 8 females and 12 males) were included in this study, their age ranged from 4048 years old. They were all suffering from missing mandibular posterior teeth. They were selected from those attending at the outpatient clinic of Oral Medicine, Periodontology, Diagnosis and Radiology department, Faculty of Dental Medicine for Girls, Al- Azhar University, Egypt. The study was approved by the Research Ethics Committee of Faculty of Dental Medicine, Al- Azhar University for Girls with a trial number (OMPDR-103-2b). 
All subjects were informed about the nature and benefits of their participation in the study. Satisfactory written consents were obtained from all the patients denoting their convenience about the scheduled research program and experiment design. A detailed medical history plus proper clinical examination were taken from each participating patient to make sure its eligibility for the study design. All patients should fulfill the inclusion criteria; Patients should have controlled type II DM, diagnosed by a physician, for at least the past 3 years, such individuals were either under using oral hypoglycemic agents and/or dietary regimen. Controlled diabetes confirmed by glycosylated blood haemoglobin, Patients should be free from any other systemic conditions that affect the periodontium or interfere with the periodontal treatment according to the modified cornell medical Index ${ }^{(10)}$, Each patient should have partially edentulous state in relation to posterior mandible with adequate bone quantity and quality at the implant site.

Exclusion criteria were poor oral hygiene and/or traumatic occlusion, history of drug abuse, catabolic drugs, radio therapy or chemo therapy, pregnant or lactating women or patients on contraceptive pills, variation in normal anatomical land marks or psychological problems, any habits that may jeopardize the regeneration process such as smoking and alcoholism, history of previous regenerative procedures in the area designated for implant therapy, systemic antibiotics or non-steroidal anti-inflammatory agents during the preceding 6 months, patients with major complications of DM and allergy to doxycycline medication were also excluded.

A randomized controlled trial (RCT) was conducted; the randomizations of patients were performed by opaque envelop and were categorized into two groups; Group I (control): Include

10 patients with type II diabetes mellitus who received one stage dental implant replacement of missing posterior tooth. Group II (test): Include 10 patients with type II diabetes mellitus who received one stage dental implant replacement of missing posterior tooth with systemic administration of a 20-mg dose of doxycycline hyclate twice daily for 3 months ${ }^{(11)}$. Preoperative radiographic examination included cone beam computed tomogram (CBCT) that was taken for every patient for initial assessment of implant placement site. Phase I periodontal therapy was performed for patients with chronic periodontitis; patients with gingivitis have undergone scaling only, patients also received oral hygiene instruction to provide an oral environment more favourable to wound healing. All patients were requested to present their medical records to confirm they were controlled type II DM, medium and long term control parameter is the value of glycosylated hemoglobin (HbA1c), and it should be at approximately within $6-8 \%{ }^{(12)}$.

All patients received one-stage, two pieces dental implant with internal-hexagon connections. Following local anesthesia of surgical area , (2\% Xylocaine with epinephrine 1:100.000), a crestal incision was made using a \#15 surgical blade, and full-thickness mucoperiosteal flaps were raised to expose the bone. Osteotomy site preparation through sequential drilling, the surgical sequence followed the protocol described by the implant company surgical kit, with reduced low speed (1200 rpm) under copious irrigation with normal saline. The implants were positioned in the osteotomy site flushing it with the margin of the crest .A total of

20 implants (10 implants in each group) placed in the center of the healed alveolar ridge in the posterior mandible were used. All implants were placed at the level of the alveolar crest using an insertion torque of $35 \mathrm{Ncm}$, good primary stability was obtained for each implant.

A healing cap (gingival former) was placed for all implants using hand torque. The mucoperiosteal flaps were adapted around the implant neck to allow non-submerged healing and were sutured with silk 
sutures. Suturing was done with interrupted sutures using non resorbable sutures (3/0 black silk) and digital intraoral postoperative radiographs taken. Post-surgical phase including application of extra oral ice packs (10-20 minutes) over the site of implant surgery to avoid hematoma formation, antibiotic prescription Augmentin1g twice/day for 5 days (625 Amoxicillin Trihydrate, 125mg clavulanc acid, GSK, Egypt) after surgery. Postoperative oral analgesic (Brufen 400mg as needed), were prescribed when needed after surgery. Patients were instructed to rinse with $0.12 \%$ chlorhexidine gluconate (Antiseptol Kahira CO. for pharm. and Chem., IND company, Cairo, Egypt) oral rinse twice daily for the first 4weeks after surgery (13). After 2 weeks the sutures were removed.

The patients were instructed to gently brush the operated area with a soft tooth brush. All patients were instructed to resume their normal mechanical oral hygiene measures one month after surgery, recall appointments were carried out weekly for first month and then monthly for proper oral hygiene reinforcement the following5 months. Three months after surgery, the healing cap was replaced by the abutment supplied by the implant system company. After that proper adjustment of the abutment and direct impression was made for fixed appliance construction by heavy and light rubber base impression material. The final crown made of porcelin fused to metal was cemented on abutment.

\section{Outcome measurements.}

CBCT was taken for each patient by using CBCT Planameca machine for CBCT imaging (Promax $3 \mathrm{dx}$ mid.Planameca Finland), the orientation beam was used to align the jaw bone parallel to the reference surface. The tube voltage was 90 $\mathrm{kV}$, the tube current was $12 \mathrm{mAs}$ and the exposure time was 4-12s according to Field of View (FOV) of pulsed exposure. The radiographs were taken before implant placement and at 6 months after the installation of implant to make densometric analysis of bone and measurement of marginal bone level. Exposure was done by the same operator under standardized protocols. It was ensured that each radiograph showed undistorted view of the featured implant in their entirety plus at least $5 \mathrm{~mm}$ of bone apical to the apex of implant. Preoperative CBCT were taken for initial assessment of implant site bone width and height, so it useful to choose the diameter and length of the implant, the relation to vital structures and measurement of bone density.

\section{Densitometric analysis:}

The grey values were measured using software (Free Ware Blue Sky 3.9) automatically illustrates the changes in the grey values in numbers by moving the pointer from a region to another on the monitor. As the titanium artefact at the bone-implant interface was within $0.5 \mathrm{~mm}$ for the all CBCT-data, the values were registered in a distance of $1.2 \mathrm{~mm}$ in a parallel manner away from the implant fixture in a spot diameter of $1 \mathrm{~mm}$ (14). The cross sectional view along the middle of the implant was used to measure the grey values in three regions buccaly and lingually.

The total length of the implant was measured and then divided into four parts in total; the first part is the most coronal $2 \mathrm{~mm}$ of the bone representing compact bone, the rest of the distance was divided into three parts representing the cervical, middle and apical thirds. The grey values of the bone around each implant were measured in these three regions of interest, each buccaly and lingually. Six recordings were measured for every implant then the average of density was calculated and tabulated (9). First, the recordings were done on the postoperative tomograph with the implant already positioned in the place. This was done to record the exact position of the implant fixture on the three different fields of view and to maximize the accuracy of the measurements on the preoperative measurements. 


\section{Linear measurements of bone level:}

On the window of CBCT, coronal and sagittal views were selected in which the margin of implant was well demarcated. The peri-implant MBL was measured in millimetres (mm) (Fig. 1)

.Using the tools from the software; a line was drawn from the reference point; the shoulder of the implant, to the first visible bone level to implant contact at mesial and distal, buccal and lingual sides. Four different recordings were measured for each implant then the mean of MBL was calculated and tabulated.

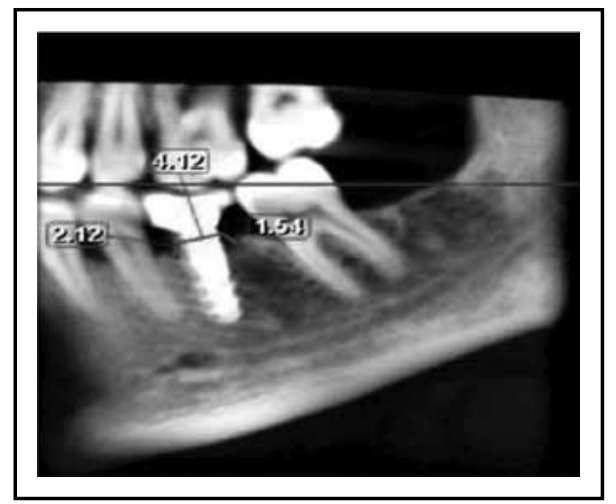

Fig. (1) Postoperative CBCT sections with linear bone measurement at 6 months follow up

\section{Statistical analysis}

Data collected were reviewed, coding and statistical analysis of collected data were done by using SPSS program (Statistical package of social science; SPSS Inc., Chicago, IL, USA) version 16 for Microsoft Windows. Descriptive statistics: Mean and standard deviation (SD) were calculated to measure central tendency and dispersion of quantitative data, Median percentiles and interquartile range for quantitative non-parametric measures. Analytic statistics: comparing groups was done using student $t$ test to determine the significance in the difference between two parametric variables, mannwhitney $\mathrm{U}$ test to determine the significance in the difference between two nonparametric variables. The results were represented in tables and graphs.

\section{RESULTS}

The present study included 20 patients with controlled type II diabetes mellitus of both genders (8 females and 12 males), their age ranged from 40-48years old, received dental implant replacement for missing posterior teeth. Group I included (3 females and 7 males) with an age range 40-44 years while group II included (5 females and 5 male) with a range of 43-48 (y). All the study patients were randomly divided into two groups; group I (control): which include 10 patients with type II diabetes mellitus who received one stage dental implant replacement of missing posterior tooth; and group II (test) which Include 10 patients with type II diabetes mellitus who received one stage dental implant replacement of missing posterior tooth with systemic administration of a 20-mg dose of doxycycline hyclate twice daily for 3 months. During the course of the study, patients in both groups exhibited consistent and comparable oral hygiene standards. All patients continued their clinical follow up visits. Regarding the treatment tolerance, the two treatment modalities were well tolerated by participating patients without any complications or side effects. All implants showed no clinical signs of peri-implant infection or detectable mobility throughout the study period.

\section{Marginal bone level (MBL)}

Table (1) illustrated the changes in mean marginal bone level. Regarding marginal bone level measurements at 6 months, there was statistically significant increase in mean marginal bone loss where group I showed higher reduction values $(2.81 \pm 0.15 \mathrm{~mm})$ in comparison with group II $(1.97 \pm 0.31 \mathrm{~mm})$. 
Table (1) The mean, standard deviation (SD) for the comparison of marginal bone level in the two groups.

\begin{tabular}{|c|c|c|c|c|c|c|}
\hline \multirow{2}{*}{\multicolumn{2}{|c|}{ Marginal bone level }} & Group I & Group II & \multirow{2}{*}{ Test value• } & \multirow{2}{*}{ P-value } & \multirow{2}{*}{ Sig. } \\
\hline & & No. $=10$ & No. $=10$ & & & \\
\hline Mesial & $\begin{array}{c}\text { Mean } \pm \text { SD } \\
\text { Range }\end{array}$ & $\begin{array}{c}3.16 \pm 0.25 \\
2.8-3.4\end{array}$ & $\begin{array}{c}1.97 \pm 0.70 \\
1.1-2.8\end{array}$ & 3.608 & 0.006 & HS \\
\hline Distal & $\begin{array}{c}\text { Mean } \pm \mathrm{SD} \\
\text { Range }\end{array}$ & $\begin{array}{c}2.98 \pm 0.48 \\
2.6-3.6\end{array}$ & $\begin{array}{c}2.05 \pm 0.44 \\
1.3-2.5\end{array}$ & 3.340 & 0.009 & HS \\
\hline Buccal & $\begin{array}{c}\text { Mean } \pm \text { SD } \\
\text { Range }\end{array}$ & $\begin{array}{c}2.78 \pm 0.08 \\
2.7-2.9\end{array}$ & $\begin{array}{c}1.70 \pm 0.48 \\
1.1-2.2\end{array}$ & 4.951 & 0.001 & HS \\
\hline Lingual & $\begin{array}{c}\text { Mean } \pm \text { SD } \\
\text { Range }\end{array}$ & $\begin{array}{c}2.30 \pm 0.28 \\
2-2.6\end{array}$ & $\begin{array}{c}2.15 \pm 0.47 \\
1.4-2.8\end{array}$ & 0.620 & 0.550 & NS \\
\hline Average & $\begin{array}{c}\text { Mean } \pm \text { SD } \\
\text { Range }\end{array}$ & $\begin{array}{c}2.81 \pm 0.15 \\
2.68-3.03\end{array}$ & $\begin{array}{c}1.97 \pm 0.31 \\
1.6-2.3\end{array}$ & 5.495 & 0.000 & HS \\
\hline
\end{tabular}

$>0.05$ NS: Non-significant; < 0.05 S: Significant; <0.01 HS: Highly significant

\section{Bone density}

Table (2) illustrated the changes in mean bone density. The mean bone density measurements within group I throughout the study period showed a statistically significant increase in measurement between the baseline and 6 months (baseline $1032.33 \pm 133.18$ and 6 months $1212.07 \pm 162.41$ ) with total increase $180 \pm 29.23$. Regarding mean bone density measurements within group II throughout the study period showed statistically significant increase in measurement between baseline and the 6 months readings (baseline $880.05 \pm 65.30$ and it was reached at 6 months $1357.33 \pm 99.20$ ) with $495 \pm$ 33.9 increase. However, the statistical analysis between the two groups in the mean bone density measurements revealed a non-significant difference between them at 6 months. The statistical analysis between the two groups in the mean percent change of bone density revealed a significant difference at 6 months results. It was $17.40 \%$ for the group I and $55.22 \%$ for group II with an increase in bone density $37 \pm .82 \%$ in group II than in group I.

Table (2) The mean, standard deviation (SD) values for the comparison of bone density in the two groups

\begin{tabular}{|c|c|c|c|c|c|c|}
\hline & & Group I & Group II & Test value & P-value & Sig. \\
\hline Bone density at base line & $\begin{array}{c}\text { Mean } \pm \text { SD } \\
\text { Range }\end{array}$ & $\begin{array}{c}1032.33 \pm 133.18 \\
890.33-1154\end{array}$ & $\begin{array}{c}880.05 \pm 65.30 \\
818-996.33\end{array}$ & 2.484 & 0.035 & $\mathrm{~S}$ \\
\hline Bone density at 6 months & $\begin{array}{l}\text { Mean } \pm \text { SD } \\
\text { Range }\end{array}$ & $\begin{array}{l}1212.07 \pm 162.41 \\
987.67-1353.33\end{array}$ & $\begin{array}{c}1357.33 \pm 99.20 \\
1220.34-1479\end{array}$ & -1.830 & 0.101 & NS \\
\hline$\%$ change & $\begin{array}{l}\text { Mean } \pm \text { SD } \\
\text { Range }\end{array}$ & $\begin{array}{c}17.40 \pm 4.78 \\
10.89-22.65\end{array}$ & $\begin{array}{l}55.22 \pm 18.40 \\
22.48-72.17\end{array}$ & -4.435 & 0.002 & HS \\
\hline \multirow[t]{2}{*}{ Paired t-test } & $\mathrm{t}$ & 7.943 & 8.165 & & & \\
\hline & p-value & 0.001 & 0.000 & & & \\
\hline
\end{tabular}

$>0.05$ NS: Non-significant; $<0.05$ S: Significant $;<0.01$ HS: Highly significant 


\section{DISCUSSION}

Diabetes mellitus is a complex, chronic systemic illness, whose complications impact significantly on quality of life and longevity. Patients with type II diabetes mellitus have an increased risk of developing periodontitis, and poor glycemic control may negatively modulate osteo-immunoinflammatory mediators in the presence of periodontitis. It creates a susceptibility condition that leads to periodontal attachment and tooth loss over time ${ }^{(15)}$. Although dental implant therapy is an effective treatment modality, the predictability relies on the osseointegration formed during the healing period and the critical dependence on bone metabolism for implant survival may be heightened in patients with $\mathrm{DM}^{(16)}$.

The use of dental implants in patients with diabetes is a debatable issue due to the adverse effects of hyperglycemia on osseointegration. Several studies have demonstrated that successful osseointegration of dental implants could be achieved in diabetic patients with well-controlled glycemic level ${ }^{(17-21)}$. However, other studies, most of which are experimental, have reported that DM could negatively affect the osseointegration of dental implants (22-24). Various host modulation therapy developed to block specific pathways of host immune and inflammatory response that primarily responsible for the periodontal tissue destruction ${ }^{(25)}$. Subantimicrobial dose doxycycline is synthetic tetracyclines, have the characteristics to inhibit collagenase enzymes, also inhibit osteoclast and osteoblast derived MMPs thus lead to reduction of alveolar bone resorption ${ }^{(26)}$.

The present study was carried to evaluate the effect of sub anti-microbial dose doxycycline on the peri-implant wound healing process. This was performed through radiographic assessment of bone density and marginal bone level at base line and six months time interval. The lack of histological investigations in humans makes understanding of the healing processes of the bone around dental implants difficult. One possible approach is to follow-up the change in bone density based on the HU of CT or the grey levels of CBCT. The frequent exposure of the patients to $\mathrm{CT}$ increases the risk of overdoses of radiation, which is the main reason for the limitation of the use of CT for monitoring the change in bone density ${ }^{(9)}$.

Hence, CBCT was used in this study for its multiple advantages. The Present randomized control trial was undergone on 20controlled type II diabetic patients with age ranged from 40-48 years; the design of the present study entailed two groups; group I (control) included 10 patients who had received one stage dental implant replacement of missing posterior tooth and group II (test) Included 10 patients who had received one stage dental implant replacement of missing posterior tooth with systemic administration of a $20-\mathrm{mg}$ dose of doxycycline hyclate (SDD) twice daily for 3 months. Well controlled type II diabetic patients were included in this study as several studies have demonstrated that successful osseointegration of dental implants could be achieved in diabetic patients with well-controlled glycemic level ${ }^{(18,19,21)}$.

Although there is some controversy over the use of antibiotics in healthy patients, these are recommended in diabetic patients in implant surgery. The reason is the impaired immune system, which can lead to wound infections and healing complications (22). So that in the current study (Augmentin 1gm) was used postoperatively. Postoperative antibiotic or analgesic use apparently has limited effect on PICF biomarkers, early implant failure, or wound healing ${ }^{(27-29)}$.

According to CBCT bone density measurements assessed at base line (before surgery) and six months postoperative period .Upon comparing the results of both groups, there was statistically significant difference in mean bone density between the two studied groups in favor of group I (1032.33 \pm 133.18$)$ where group II $(880.05 \pm 65.30)$ at base line. This may be due to ineffective randomization of bone density before implant placement. 
However, a significant increase in density of bone around dental implants was recorded for both groups at six months with maximum increase in mean value in favor of group II (1357.33 \pm 99.20$)$ where group I $(1212.07 \pm 162.41)$ respectively, reflecting more activation or increase of the osteoblast cells and consequent bone apposition. The result of this study was in agreement with previous study that approved that bone density increased around dental implant after placement due to increase in mineralization of tissue ${ }^{(30)}$. Another study related the increase in bone density due to lateral bone compression by implant placement rather than increase in calcified tissue after implant placement ${ }^{(14)}$.

In addition, inter-group comparison revealed that group II showed high percentage of increase in bone density (\%55.22) while group I recorded percentage of increase (\%17.4) respectively. This improvement in group II treated with SDD may be attributed to the pro-anabolic activity of SDD regarding bone metabolism revealed by the following studies. Doxycycline was reported to act as an osteogenic agent enhancing new bone formation and regeneration by improving type 1 collagen synthesis as well as other osteogenic factors (i.e. bone morphogenetic proteins) ${ }^{(31)}$. The long-term exposure of human bone marrow osteoblastic cells to doxycycline induces a significant increase in the number of osteoblastic cells. Doxycycline caused an increase in the cell growth, in the maintenance of alkaline phosphatase activity and higher abundance of mineral deposition ${ }^{(32)}$.

Other in vitro results indicated the effect of doxycycline on osteoblastic proliferation and differentiation; the authors of that study have concluded that doxycycline appears to enhance maturation and differentiation, rather than proliferation of osteoblast ${ }^{(33)}$. Moreover, low concentrations of doxycycline induce an osteoblastic differentiation similar to that obtained from cells exposure to bone morphogenic protein-2 (BMP-2). Doxycycline was also reported to modulate positively osteoprogenitor cells from human femoral cancellous bone ${ }^{(34)}$. Previous used low doses of orally administered doxycycline for 7 days after molar extraction in Wistar rats. A histomorphometric analysis was used to evaluate new bone formation inside the alveolar socket. The findings showed that the percentage of new bone formation enhanced significantly on days 7 and 14 than control group ${ }^{(35)}$.

In accordance with the present study, a histomorphometric study in murine maxillae clearly showed that the doxycycline treated implant surface locally, was surrounded by more new bone within the threads than untreated group and had a higher bone-to-implant contact (BIC). Furthermore, the scanning electron microscope (SEM) and energy dispersive X-ray spectroscopy (EDS) analyses revealed that although osseointegration of the implant was successfully achieved in the both groups, new bone formation of doxycycline group was superior to the one of hydroxyapatite group ${ }^{(36)}$.

Crestal bone level has been documented as one of the important factors that affect the long term prognosis of implant supported restoration ${ }^{(38)}$. The peri-implant bone quantity and quality not only affects osseointegration phase, but also influences the overlying soft tissues architecture. Assessment of marginal bone levels has become an integral part of the evaluation of the implant patient and is usually asignifcant indicator of implant health ${ }^{(39)}$. It has been demonstrated that following implant surgery, remodeling occurs and is characterized by a reduction in bone dimension, both horizontally and vertically ${ }^{\left({ }^{40}\right)}$.In the present study, there was statistically significant increase in mean marginal bone loss where group I showed higher reduction values $(2.81 \pm 0.15)$ on comparison with group II $(1.97 \pm 0.31)$ respectively at six months. This might attributed to remodeling process of the alveolar bone that is initiated by the insertion of the implant and the activation of the osteoclasts.

The marginal bone loss recorded in the present study was in accordance with previous studies ${ }^{(41,42)}$ where the former reported the maximum bone loss 
in 70patients at six months with three years of follow up, the later recorded $86 \%$ of bone loss was taken place in the first six months period. They attributed this bone loss to peri-implant bone remodeling after implant placement is more accentuated in the first six months after surgery. The lower marginal bone loss records were reported in group II in this study might be attributed to the inhibition of the MMPs and bone resorption by SDD administration. During the process of bone remodeling, osteoblasts can initiate bone resorption by synthesizing the neutral proteinases including MMPs which can degrade osteoid. MMPs such as MMP-1, MMP-13 and MMP-14, which can degrade type I collagen of demineralized bone, are also produced by osteoclasts. The inhibition of the MMPs is the most widely documented and well characterized nonantibiotic property of doxycycline ${ }^{(43-45)}$.

In addition, previous study ${ }^{(46)}$ showed that doxycycline decreases mononuclear inflammatory infiltrates and osteoclast numbers, thereby preventing inflammatory bone resorption. Furthermore, ${ }^{(47)}$ it was reported that doxycycline induces osteoclasts apoptosis, which occurs independently of the inhibition of MMPs ${ }^{(47)}$. Moreover, another study showed doxycycline effectively inhibit osteoclastogenesis and to affect mature osteoclast fate ${ }^{(48)}$.

\section{CONCLUSION}

According to the literature and within the limits of the available investigations; in the light of finding of this current study, both groups showed favorable clinical radiographic and biochemical changes with group II diabetic patients received dental implant with SDD superior results than group I diabetic patients who received dental implant without SDD administration .

\section{REFERENCES}

1. Javed F, Romanos GE. Impact of diabetes mellitus and glycemic control on the osseointegration of dental implants: a systematic literature review. J Periodontol. 2009; 80:1719-1730.
2. Preeti AK, Manish K. Rupal J. Shah. Rehabilitative Considerations for Dental Implantsin the Diabetic Patient. J Indian Prostho dont Soc 13:175-183.

3. Preshaw PM. Host response modulation in periodontics. Periodontology 2000. 2008; 48: 92-110.

4. Isoda K, Ayukawa Y, Tsukiyama Y, Sogo M, Matsushita Y, Koyano K. Relationship between the bone densities estimated by cone-beam computed tomography and the primary stability of dental implants. Clin Oral Implants Res 2012; 23:832-836.

5. González-Martín O, Lee EA, Veltri M: CBCT fractal dimension changes at the apex of immediate implants placed using undersized drilling. Clin. Oral Implants Res 2012; 23: 954-95.

6. Hsu JT, Chang HW, Huang HL, Yu JH, Li YF, Tu MG: Bone density changes around teeth during orthodontic treatment. Clin Oral Investig 2011; 15:511-519

7. Monje A, Monje F, Gonzalez-Garcı R, GalindoMoreno P, Rodriguez-Salvanes F, Wang HL. Comparison between microcomputed tomography and cone-beam computed tomography radiologic bone to assess atrophic posterior maxilla density and microarchitecture. Clin Oral Implants Res 2014; 25: 723-728.

8. Hasan I, Dominiak M, Blaszczyszyn A, Bourauel C, Gedrange T, Heinemann F. Radiographic evaluation of bone density around immediately loaded implants. Ann Anat 2015; 199:52-57.

9. Kholsa S. Minireview: the Opg/Rankl/Rank system. Endocrinology 2001; 142: 5050-5055.

10. Abramson, J. H. The Cornell medical index as an epidemiological tool, Am J Pub H and the Nat H 1966; 56: 287-298.

11. Caton J, Ryan ME. Clinical studies on the management of periodontal diseases utilizing subantimicrobial dose doxycycline (SDD). Pharmacol Res .2011; 63: 114-120.

12. Busenlechner D, Furhauser R, Haas R, Watzek G, Mailath G, Pommer B. Long-term implant success at the Academy for Oral Implantology: 8-year follow-up and risk factor analysis. J Periodontal Implant Sci 2014; 44:102-8.

13. Lambert $\mathrm{P}$, Morris $\mathrm{H}$, Ochi S: The influence of $0.12 \%$ chlorhexidine digluconate rinses on the incidence of infectious complications and implant success. J Oral Maxillofac Surg 1997; 55:25-30.

14. Yassir Elkhidir, Sun Wei, Li Suyang, Mengqing Xie and Cheng Yang. Feasibility of CBCT in Evaluating Bone Density of Dental Implant Placement Sites. RRJDS. 2017; 5:87-91 
15. Schwartz A. Diabetes mellitus: does it affect bone? CTI 2003; 73:515-9.

16. Oates T, Huynh-Ba G, Vargas A, Alexander P, Feine J. A critical review of diabetes, glycemic control, and dental implant therapy. Clin Oral Implants Res 2013; 24:117-27.

17. Olson JW, Shernoff AF, Tarlow JL, Colwell JA, Scheetz JP, Bingham SF. Dental endosseous implant assessments in a type 2 diabetic population: A prospective study. Int $\mathbf{J}$ Oral Maxillofac Implants 2000; 15:811-818.

18. Peled M, Ardekian L, Tagger-Green N, Gutmacher Z, Machtei EE. Dental implants in patients with type 2 diabetes mellitus: A clinical study. Implant Dent 2003; 12:116-122.

19. Casap N, Nimri S, Ziv E, Sela J, Samuni Y. Type 2 diabetes has minimal effect on osseointegration of titanium implants in Psammomys obesus. Clin Oral Implants Res 2008; 19:458-64.

20. Balshi SF, Wolfinger GJ, Balshi TJ. An examination of immediately loaded dental implant stability in the diabetic patient using resonance frequency analysis (RFA). Quintessence Int 2007; 38:271-9.

21. Tawil G, Younan R, Azar P, Sleilati G. Conventional and advanced implant treatment in the type II diabetic patient: surgical protocol and long-term clinical results. Int J Oral Maxillofac Implants 2008; 23:744-52.

22. Morris HF, Ochi S, Winkler S. Implant survival in patients with type 2 diabetes. Ann Periodontol 2000; 5:157-65.

23. Mccracken MS, Aponte-Wesson R, Chavali R, Lemons JE McCracken. Bone associated with implants in diabetic and insulin-treated rats. Clin Oral Implants Res 2006; 17: 495-500.

24. Hasegawa H, Ozawa S, Hashimoto K, Takeichi T, Ogawa T. Type 2 diabetes impairs implant osseointegration capacity in rats. Int J Oral Maxillofac Implants 2008; 23:237-246.

25. Reddy MS, Geurs NC, Gunsolley JC. Periodontal host modulation with antiproteinase, anti- inflammatory, and bone-sparing agents. A systematic review. Ann Periodontol 2003; 8:12-37.

26. Preshaw PM, Hefti AF, Novak MJ. Subantimicrobial dose doxycycline enhances the efficacy of scaling and root planing in chronic periodontitis: a multicenter trial. $\mathrm{J}$ Periodontol 2004;75:1068-76.

27. Khoury SB, Thomas L, Walters JD, Sheridan JF, Leblebicioglu B. Early wound healing following one-stage dental implant placement with and without antibiotic prophylaxis: a pilot study. J Periodontol 2008; 79:1904-1912.
28. Alissa R, Sakka S, Oliver R, Horner K, Esposito M, Worthington HV, Coulthard P. Influence of ibuprofen on bone healing around dental implants: a randomized double-blind placebo controlled clinical study. Eur J Oral Implantol 2009; 2:185-199.

29. Waasdorp JA, Evian CI, Mandracchia M. Immediate placement of implants into infected sites: a systematic review of the literature. J. Periodontol 2010; 81:801-806.

30. Barunawarty Y. Assessment of the increased calcification of jaw bone with CT-Scan after dental implant placement. Imaging Sci Dent 2011; 41: 59- 62.

31. Golub L, Lee H-M, Greenwald R, Ryan M, Sorsa T, Salo T. A matrix metalloproteinase inhibitor reduces bone-type collagen degradation fragments and specific collagenases in gingival crevicular fluid during adult periodontitis. IR 1997; 46:310-9.

32. Gomes PS, Fernandes MH. Effect of therapeutic levels of doxycycline and minocycline in the proliferation and differentiation of human bone marrow osteoblastic cells. AOB 2007; 52:251-9.

33. Almazin SM, Dziak R, Andreana S. The effect of doxycycline hyclate, chlorhexidine gluconate, and minocycline hydrochloride on osteoblastic proliferation and differentiation in vitro. J Periodontol 2009; 80: 999_ 1005 .

34. Eglence A, Colterjohn N, Duivenvoorden WC, Ghert M, Singh G. Effect of bone morphogenetic protein-2 and doxycycline on the differentiation of osteoprogenitors from human femoral bone. Open Bone J. 2009; 1:1-7.

35. Shahabooei M, Razavi SM, Minaiyan M. A histomorphometric study of the effect of doxycycline and erythromycin on bone formation in dental alveolar socket of rat. Adv Biomed Res 2015; 4:71.

36. Lin Ding, Peng Zhang, Xin Wang, Jia Hao, Kazuhiro Aoki, Shinji Kuroda, Shohei Kasugai Effect of doxycyclinetreated hydroxyapatite surface on bone apposition: A histomophometric study in murine maxillae. DMJ 2017; 11: 1- 9 .

37. Yiming Liu, Jing Hu, Biao Liu, Xiliang Jiang, Yunfeng Li. peri-implant bone mass and improved trabecular microarchitecture. The effect of osteoprotegerin on implant osseointegration in ovariectomized rats. Arch Med Sci 2017; 13, 2: 489-495.

38. Sunitha RV, Ramakrishnan T, Kumar S, Emmadi P. Soft tissue preservation and crestal bone loss around singletooth implants. J Oral Implantol 2008; 34:223-229. 
39. PriyanKa Boora, Manu rathee, MohaneeSh Bhoria. Effect of Platelet Rich Fibrin on Peri- implant Soft Tissue and Crestal Bone. JCDR 2015; 9: 18-21.

40. Cavallaro JS Jr. Implant survival and radiographic analysis of proximal bone levels surrounding a contemporary dental implant. Implant Dent 2011; 20: 146-5.

41. Lee DW, Choi YS, Park KH, Kim CS, Moon IS. Effect of microthread on the maintenance of marginal bone level: a 3-year prospective study. Clin Oral Implants Res 2007; 18:465-70.

42. Cochran DL, Nummikoski V, Schoolfeld JD, Jones AA, Oates TW. A prospective multicenter 5-year radiographic evaluation of crestal bone levels over time in 596 dental implants placed in 192 patients. J Periodontol 2009; 80:725-33.

43. Choi DH, Moon IS. Effects of sub-antimicrobial dose doxycycline therapy on crevicular fluid MMP-8 and gingival tissue MMP-9, TIMP-1 and IL-6 levels in chronic periodontitis. J Periodont Res 2004; 39: 20-26.

44. Kinugawa S, Koide M, Kobayashi Y. Tetracyclines convert the osteoclasticdifferentiation pathway of progenitor cells to produce dendritic cell-like cells. J Immunol 2012; 188: 1772-1781.

45. Nurdan O, Ceren G. Chemical inhibition of matrix metalloproteinases for periodontal treatment. Antiinflamm Antiallergy Agents Med Chem 2015; 2: 21-26.

46. Bezerra MM, Brito GA, Ribeiro RA. Low-dose doxycycline prevents inflammatory bone resorption in rats. Braz J Med Biol Res 2002; 35: 613-616.

47. Holmes SG, Still K, Buttle DJ, Bishop NJ. Chemically modified tetracyclines act through multiple mechanisms directly on osteoclast precursors. Bone 2004; 35:471-8.

48. Zhang C, Tang TT, Ren WP. Inhibiting wear particlesinduced osteolysis with doxycycline. Acta Pharmacol Sin 2007; 28:1603-1610. 